\title{
Anomalous Orbital Admixture in Ammine Complexes
}

\author{
Tao Zeng, Kyle M. Lancaster, Nandini Ananth, \\ Roald Hoffmann ${ }^{1}$ \\ Department of Chemistry and Chemical Biology, \\ Cornell University, Ithaca, NY, 14853, United States
}

One can just feel the desire to understand inorganic molecules in Mike Mingos' work. Thank you for this gift to all of us.

\section{Abstract}

A detailed orbital analysis of two seemingly ordinary classes of complexes of group 12 dications, $\left[\mathrm{M}\left(\mathrm{NH}_{3}\right)_{4}\right]^{2+}$ and $\left[\mathrm{M}\left(\mathrm{PH}_{3}\right)_{4}\right]^{2+}, \mathrm{M}=\mathrm{Zn}, \mathrm{Cd}$, $\mathrm{Hg}$, holds a surprise. The $\mathrm{PH}_{3}$ complexes are text-book examples of tetrahedral bonding, but in the ammine complexes calculations reveal a remarkable degree of mixing between occupied $\mathrm{M}(n-1) d$ and $\mathrm{NH}_{3} \sigma_{\pi}$ orbitals. A perturbation-based Fock matrix examination traces the origin of this mixing to an energy resonance and improved overlap of interacting orbitals for $\mathrm{NH}_{3}$ ligands. The possibility of probing this anomalous mixing with valence-to-core X-ray emission spectroscopy (V2C XES) is discussed.

Keywords: Ammine Ligand; Tetrahedral coordination; $\pi$-type interaction; Energy resonance; Valence-to-core emission

${ }^{1}$ Corresponding Author: rh34@cornell.edu 


\section{Introduction}

In the course of searching for an inverted ligand-field splitting, ${ }^{1}$ we had occasion to look at the electronic structure of a seemingly normal series of Group $12 \mathrm{M}(\mathrm{II})$ complexes - $\left[\mathrm{M}\left(\mathrm{EH}_{3}\right)_{4}\right]^{2+}, \mathrm{E}=\mathrm{N}, \mathrm{P}, \mathrm{As}, \mathrm{Sb}, \mathrm{Bi} ; \mathrm{M}=$ $\mathrm{Zn}, \mathrm{Cd}, \mathrm{Hg}$. Phosphine $\left(\mathrm{PH}_{3}\right)$ complexes are uncommon, but $\mathrm{PR}_{3}$ ligands are a workhorse of coordination and organometallic chemistry. ${ }^{2-6}$ The ammine $\left(\mathrm{NH}_{3}\right)$ complexes are common, especially the $\mathrm{Zn}$ ones, and a typical structure of these complexes is shown in Fig. 1. The orbital mixing in these $\left[\mathrm{M}\left(\mathrm{NH}_{3}\right)_{4}\right]^{2+}$ ions, however, turns out, as we will see, to be atypical.

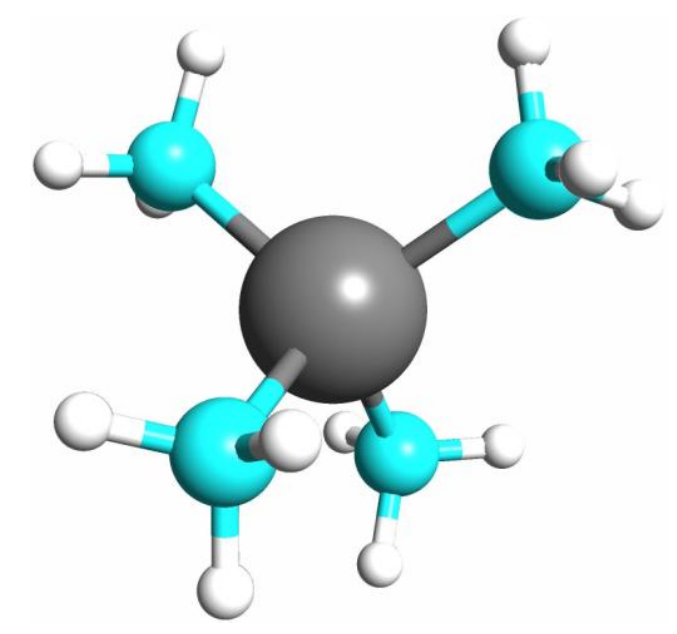

Fig. 1. $\left[\mathrm{Zn}\left(\mathrm{NH}_{3}\right)_{4}\right]^{2+}$.

Usually, $\mathrm{EH}_{3}, \mathrm{E}=$ Group 15 elements, are considered classic Lewis bases: $\sigma$-donor ligands that bond with metals primarily through high-lying lone-pair orbitals localized on the $\mathrm{E}$ atom. In a 4-coordinate complex with rigorous $T_{d}$ symmetry, the lone pairs generate symmetry-adapted $a_{1}+t_{2}$ orbital combinations. These then interact with metal orbitals of the same symmetry and induce $t_{2}$-e splitting, leaving the $e$-type $(n-1) d$ orbitals as noninteracting orbitals (see Fig. 2). ${ }^{7}$ As Landis and Weinhold have pointed out, ${ }^{8}$ the contribution of the metal $n p$ orbitals to the two low-lying $t_{2}$ levels is small. 


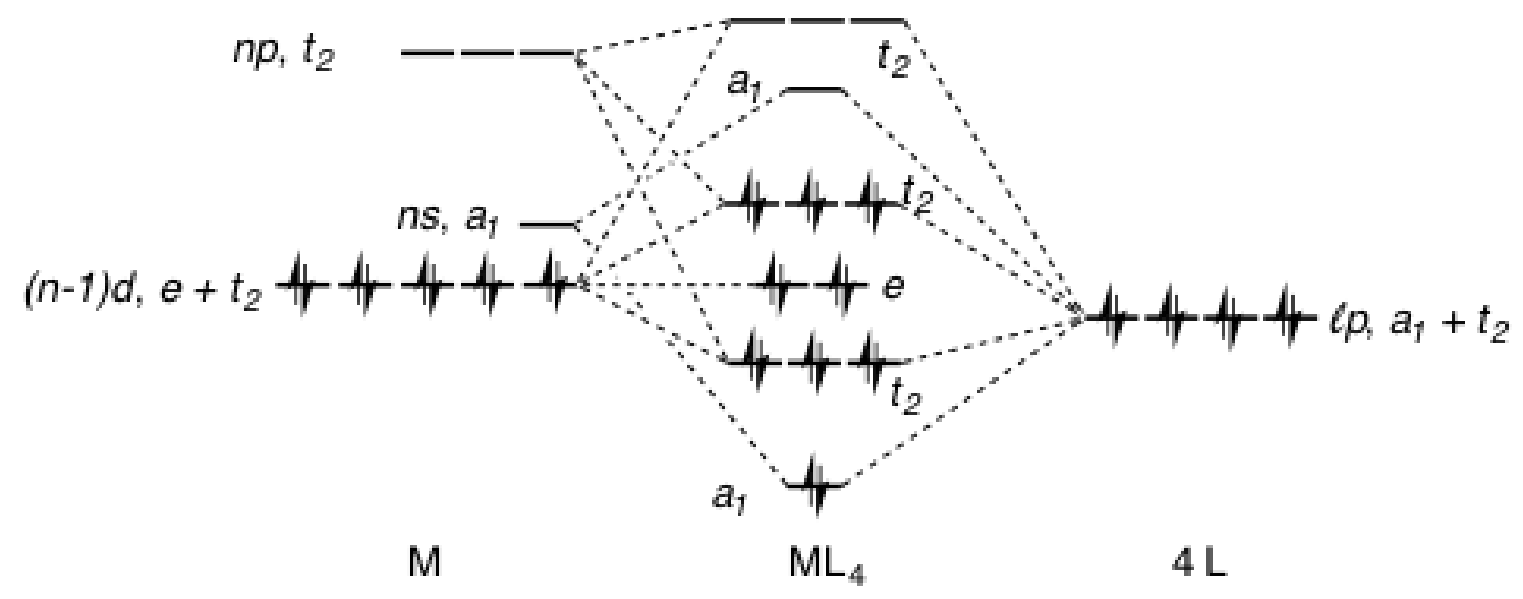

Fig. 2. Typical orbital interaction diagram for $d^{10}$ tetrahedral $\mathrm{ML}_{4}$ complexes. Here "lp" stands for lone-pair orbitals of the ligands.

$\mathrm{EH}_{3}$ ligands are not thought to engage in $\pi$-bonding, but a detailed orbital analysis suggests reconsideration of this perspective. In addition to the lone pair on $\mathrm{E}$, the $\mathrm{EH}_{3}$ ligands contain three delocalized $\mathrm{E}-\mathrm{H}$ bonding orbitals, shown in Fig. 3 for $\mathrm{NH}_{3}$, with $a_{1}+e$ symmetry in the $C_{3 v}$ point group of the ligand, and a set of corresponding $\mathrm{E}-\mathrm{H}$ antibonding orbitals. The $e$ combination, containing $\mathrm{N} 2 p_{x / y}$, has $\pi$ symmetry, so we will call the orbital set $\sigma_{\pi}$ i in contrast, the $a_{1}$ combination contains $\mathrm{N} 2 \mathrm{~s}$ and $2 p_{z}$ and we call it $\sigma_{\sigma}$ In these two labels, the inline $\sigma$ indicates the $\mathrm{N}-\mathrm{H}$ bond type, while the subscripts $\sigma$ and $\pi$ characterize the symmetry of the orbitals with respect to $\mathrm{N}-\mathrm{M}$ bonding when $\mathrm{NH}_{3}$ serves as a ligand.

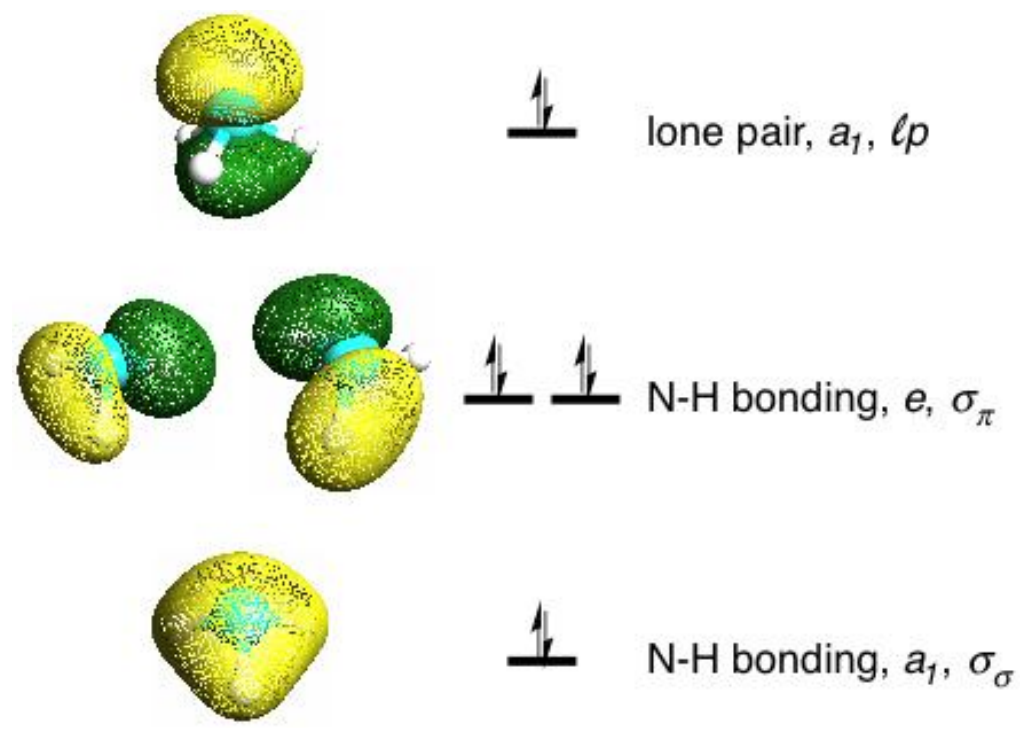


Fig. 3. The valence occupied orbitals of $\mathrm{NH}_{3}$, their irreducible representations, and the labels $\left(l p, \sigma_{\pi}\right.$, and $\left.\sigma_{\sigma}\right)$ used in the discussions below.

In the $T_{d}$ point group of the $\left[\mathrm{M}\left(\mathrm{EH}_{3}\right)_{4}\right]^{2+}$ ions, the eight $\sigma_{\pi}$ orbitals combine to form $e, t_{1}$, and $t_{2}$ symmetry-adapted orbitals. Five $\left(e, t_{2}\right)$ of the eight can interact with the valence $d$-orbitals of the metal, in the standard $\pi$-bonding picture of tetrahedral complexes familiar to the community for 50 years. ${ }^{9}$ While $\pi$-type metal-ligand bonding is important for $\pi$-acceptors such as $\mathrm{CO}, \mathrm{CN}^{-}$, and $\mathrm{PF}_{3}$, and for $\pi$-donors such as $\mathrm{O}^{2-}, \mathrm{Cl}^{-}$, and $\mathrm{SR}$, neither $\mathrm{NH}_{3}$ nor $\mathrm{PH}_{3}$ are recognized as particularly good $\pi$-donor or acceptor ligands. The $\mathrm{E}-\mathrm{H}$ bonding orbitals are thought to be too low in energy to interact with the valence $d$-orbitals of the metal. We examine the validity of these ideas with detailed calculations.

\section{The Expected Behavior of Phosphine Ligands}

The traditional orbital mixing picture outlined above proves correct for the $\left[\mathrm{M}\left(\mathrm{PH}_{3}\right)_{4}\right]^{2+}$ series. The highest-lying occupied molecular orbital (MO) energies are shown in Table 1. Also shown are the results of a Natural Population Analysis (NPA) ${ }^{10}$ that describes the composition of the molecular orbitals (MOs) as percentage contributions from the metal (M\%) and the four ligands' (4L\%) orbitals. We use DFT with the M06 functional to generate the results reported here, and provide additional details of calculations in the Theoretical Methods section at the end of the paper. The low orbital energies stem from the +2 charge of the ionic complexes. We probed the effect of the overall charge by calculations on a neutral $\left[\mathrm{Zn}\left(\mathrm{PH}_{3}\right)_{4}\right]\left(\mathrm{BF}_{4}\right)_{2}$ molecule. As expected, the orbital energies increase, but the orbital character remains essentially unchanged.

Table 1. Energies of the highest lying occupied orbitals of the three Group 12 dication phosphine complexes listed in the first column, and the percentage populations on the metals (M\%) and the four ligands (4L\%) in each orbital from NPA. The approximate character of each orbital is specified in the last column with " $a b$ " standing for antibonding, " $b$ " for 
bonding, "ni" for noninteracting, " $l p$ " for lone-pair on the ligand, and " $\sigma_{\pi}$ " for the $\pi$-like $\mathrm{P}-\mathrm{H}$ bonding orbital in the $\mathrm{PH}_{3}$ ligands. The " $s$ ", " $p$ ", and " $d$ " symbols indicate the type of metal valence orbital.

\begin{tabular}{|c|c|c|c|c|c|}
\hline & Orbital & $\mathrm{E} / \mathrm{eV}$ & $\mathrm{M} \%$ & 4L\% & Character \\
\hline \multirow{7}{*}[\mathrm{Zn}(\mathrm{PH}_{3})_{4}]{$^{2+}$} & $t_{2}$ & -16.63 & 4 & 96 & $l p-4 p b$ \\
\hline & $t_{1}$ & -19.35 & 0 & 100 & $\sigma_{\pi} n i$ \\
\hline & $e$ & -19.54 & 1 & 99 & $\sigma_{\pi} n i$ \\
\hline & $t_{2}$ & -19.57 & 0 & 100 & $\sigma_{\pi} n i$ \\
\hline & $a_{1}$ & -19.67 & 35 & 65 & $l p-4 s b$ \\
\hline & $e$ & -22.97 & 99 & 1 & $3 d n i$ \\
\hline & $t_{2}$ & -23.02 & 96 & 4 & $3 d n i$ \\
\hline \multirow{7}{*}[\mathrm{Cd}(\mathrm{PH}_{3})_{4}]{$^{2+}$} & $t_{2}$ & -16.37 & 4 & 96 & $l p-5 p b$ \\
\hline & $a_{1}$ & -18.99 & 33 & 67 & $l p-5 s b$ \\
\hline & $t_{1}$ & -19.17 & 0 & 100 & $\sigma_{\pi} n i$ \\
\hline & $e$ & -19.29 & 1 & 99 & $\sigma_{\pi} n i$ \\
\hline & $t_{2}$ & -19.32 & 0 & 100 & $\sigma_{\pi} n i$ \\
\hline & $e$ & -23.78 & 99 & 1 & $4 d n i$ \\
\hline & $t_{2}$ & -23.81 & 93 & 7 & $4 d n i$ \\
\hline \multirow{7}{*}[\mathrm{Hg}(\mathrm{PH}_{3})_{4}]{$^{2+}$} & $t_{2}$ & -16.02 & 7 & 93 & $\ell p-5 d a b / \ell p-6 p b$ \\
\hline & $t_{1}$ & -19.12 & 0 & 100 & $\sigma_{\pi} n i$ \\
\hline & $e$ & -19.14 & 4 & 96 & $\sigma_{\pi} n i$ \\
\hline & $t_{2}$ & -19.22 & 0 & 100 & $\sigma_{\pi} n i$ \\
\hline & $a_{1}$ & -19.23 & 26 & 74 & $\ell p-6 s b$ \\
\hline & $e$ & -21.53 & 96 & 4 & $5 d n i$ \\
\hline & $t_{2}$ & -21.67 & 92 & 8 & weak $l p-5 d b$ \\
\hline
\end{tabular}


Table 1 includes a larger number of interacting orbitals than are shown in Fig. 2. The corresponding modified version of the interaction diagram that includes the $\sigma_{\pi}$ orbitals of the ligands is shown in Fig. 4. Note that in this diagram, the metal orbital energies are lowered to reflect the +2 charge concentrated on the electrpositive metal center.

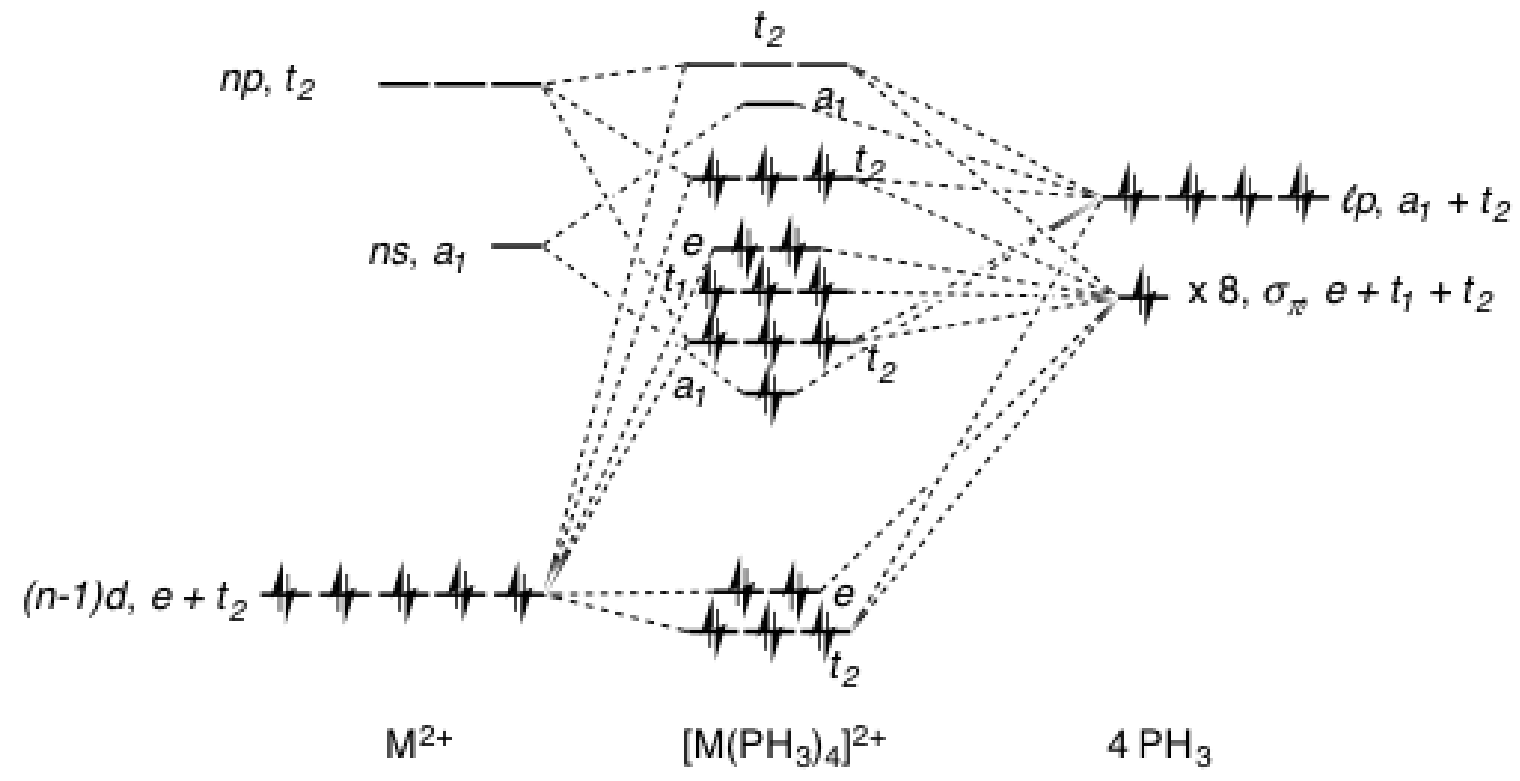

Fig. 4. Schematic orbital interaction diagram for $\left[\mathrm{M}\left(\mathrm{PH}_{3}\right)_{4}\right]^{2+}$. The $a_{1}, t_{2}, e$, and $t_{1}$ levels in the $\left[\mathrm{M}\left(\mathrm{PH}_{3}\right)_{4}\right]^{2+}$ ranging from $3^{\text {rd }}$ to $6^{\text {th }}$ in increasing order of energy are close in energy (Table 1 ) and their relative positions in this schematic diagram do not represent their actual energy ordering.

$\mathrm{ML}_{4}$ bonding occurs mainly through the $a_{1} \mathrm{MO}$, a bonding combination of the $\mathrm{M} n s$ and the $\mathrm{PH}_{3}$ lone pairs with 35:65, 33:67, and 26:74 M:4L mixing in the three phosphine ions. The $t_{2}$ highest occupied $\mathrm{MO}$ (HOMO) is less involved in bonding, and has contributions mainly from the ligand lone pairs, with a small admixture (4-7\%) of $M n p$ (with bonding character) and ( $n-1) d$ (with antibonding character).

It is clear from Table 1 that the $\mathrm{PH}_{3} \sigma_{\pi}$ orbitals are largely unchanged from the individual ligand orbitals. We label these orbitals noninteracting (ni). The $n i, t_{1}+t_{2}+e, \sigma_{\pi}$ set is never split by more than $0.22 \mathrm{eV}$, and is $96-$ $100 \%$ localized on the four ligands for the Group 12 dication series. 
To summarize, the orbitals of $\left[\mathrm{M}\left(\mathrm{PH}_{3}\right)_{4}\right]^{2+}$ are textbook - dative bonding to the metal is largely through the phosphine lone pairs, and the $\mathrm{PH}_{3} \sigma_{\pi}$ orbitals do not engage in $\pi$-bonding. We also calculate the structure of the phosphine ion complexes and find some interesting features; these are discussed in a separate section below.

\section{The Unusual Behavior of Ammine Ligands}

Having set the stage with the $\mathrm{PH}_{3}$ ligand, one can appreciate our surprise when we investigated the nature of bonding for a similarly "normal" ligand, ammonia. Table 2 shows our calculated results for orbital energies and compositions in $\left[\mathrm{M}\left(\mathrm{NH}_{3}\right)_{4}\right]^{2+}, \mathrm{M}=\mathrm{Zn}, \mathrm{Cd}, \mathrm{Hg}$. Like the phosphine complexes, the geometrical structures of ammine complexes are also calculated and will be discussed below.

Table 2. Energies of the highest lying occupied orbitals of the three Group 12 dication ammine complexes listed in the first column, and the percentage populations on the metals (M\%)and ligands (4L\%) in each orbital from NPA. The character of each orbital is specified in the last column with " $a b$ " standing for antibonding, " $b$ " for bonding, " $n i$ " for noninteracting, " $l p$ " for lone-pair on the ligand, " $\sigma_{\pi}$ " for the $\pi$-like $\mathrm{N}-\mathrm{H}$ bonding orbital in the $\mathrm{NH}_{3}$ ligands. The " $s$ ", " $p$ ", and " $d$ " symbols indicate the type of metal valence orbitals.

\begin{tabular}{|c|c|r|r|r|r|}
\hline & Orbital & $\mathrm{E} / \mathrm{eV}$ & $\mathrm{M} \%$ & $4 \mathrm{~L} \%$ & Character \\
\hline & $t_{2}$ & -18.58 & 12 & 88 & $\ell p-4 p b / \ell p-3 d a b$ \\
\cline { 2 - 6 } & $a_{1}$ & -21.43 & 20 & 80 & $\ell p-4 s b$ \\
\cline { 2 - 6 }$\left[\mathrm{Zn}\left(\mathrm{NH}_{3}\right)_{4}\right]^{2+}$ & $e$ & -21.98 & 59 & 41 & $\sigma_{\pi}-3 d a b$ \\
\cline { 2 - 6 } & $t_{1}$ & -22.52 & 0 & 100 & $\sigma_{\pi} n i$ \\
\cline { 2 - 6 } & $t_{2}$ & -22.61 & 30 & 70 & $\sigma_{\pi}-3 d a b$ \\
\cline { 2 - 6 } & $t_{2}$ & -23.19 & 58 & 42 & $\sigma_{\pi}-3 d b / \ell p-3 d b$ \\
\cline { 2 - 6 } & $e$ & -23.36 & 41 & 59 & $\sigma_{\pi}-3 d b$ \\
\hline$\left[\mathrm{Cd}\left(\mathrm{NH}_{3}\right)_{4}\right]^{2+}$ & $t_{2}$ & -18.09 & 10 & 90 & $\ell p-5 p b / \ell p-4 d a b$ \\
\hline
\end{tabular}




\begin{tabular}{|c|c|c|c|c|c|}
\hline & $a_{1}$ & -20.50 & 19 & 81 & $l p-5 s b$ \\
\hline & $e$ & -22.02 & 23 & 77 & $\sigma_{\pi}-4 d a b$ \\
\hline & $t_{1}$ & -22.28 & 0 & 100 & $\sigma_{\pi} n i$ \\
\hline & $t_{2}$ & -22.37 & 4 & 96 & $\sigma_{\pi}-4 d a b$ \\
\hline & e & -23.82 & 77 & 23 & $\sigma_{\pi}-4 d b$ \\
\hline & $t_{2}$ & -23.87 & 85 & 15 & $\sigma_{\pi}-4 d b / l p-4 d b$ \\
\hline \multirow{7}{*}[\mathrm{Hg}(\mathrm{NH}_{3})_{4}]{$^{2+}$} & $t_{2}$ & -17.57 & 18 & 82 & $\ell p-6 p b / \ell p-5 d a b$ \\
\hline & $a_{1}$ & -20.47 & 13 & 87 & $L p-6 s b$ \\
\hline & $e$ & -20.98 & 77 & 23 & $\sigma_{\pi}-5 d a b$ \\
\hline & $t_{2}$ & -21.78 & 60 & 40 & $\sigma_{\pi}-5 d a b$ \\
\hline & $t_{1}$ & -22.20 & 0 & 100 & $\sigma_{\pi} n i$ \\
\hline & $t_{2}$ & -22.49 & 22 & 78 & $\sigma_{\pi}-5 d b / l p-5 d b$ \\
\hline & $e$ & -22.70 & 23 & 77 & $\sigma_{\pi}-5 d b$ \\
\hline
\end{tabular}

The calculated MOs involving $\sigma_{\pi}$ in the three tetraammine dication complexes are far from pure ligand or pure metal. As Table 2 shows, the high-lying $e$ orbitals have M:4L mixings of 59:41, 23:77, and 77:23, definitely more substantial than those listed in Table 1 . Their low-lying counterparts, which in the phosphine cases were pure metal $(n-1) d$, have complementary mixings of 41:59, 77:23, and 23:77. These pronounced orbital mixings point to unexpected $\pi$-interaction in the ammine complexes.

\section{The Origin of $\sigma_{\pi}$ and $(n-1) d$ Mixing in Ammine Complexes}

We start by investigating the normal behavior of the phosphine ions and the absence of $\sigma_{\pi}-(n-1) d$ interaction in Table 1 . We focus on the $e$ irreducible representation of the $T_{d}$ point group that involves mixing $(n-1) d$ and linear combinations of the $\sigma_{\pi}$ orbitals, since this interaction between $e$ type orbitals is not contaminated by the interactions with $l p-(n-1) d$ and $\ell p$ - 
$n s$. In the upper half of Table 3 we present the diagonal and off-diagonal matrix elements of the Fock operators of the $\sigma_{\pi}$ and $(n-1) d$ orbitals of $\left[\mathrm{M}\left(\mathrm{PH}_{3}\right)_{4}\right]^{2+}$ at their optimized structures. The Coulomb and exchange operators within the Fock operator are constructed using the occupied MOs from the converged DFT calculations of the respective ions. The diagonal elements indicate the orbital energies in the environment of the ion complexes and the off-diagonal elements gage the interaction strength between the orbitals.

The $\sigma_{\pi}$ and $(n-1) d$ orbitals are obtained from calculations of neutral $\left(\mathrm{PH}_{3}\right)_{4}$ and metal atoms, with the four $\mathrm{PH}_{3}$ retaining the geometries of the respective $\left[\mathrm{M}\left(\mathrm{PH}_{3}\right)_{4}\right]^{2+}$ ions. The $\sigma_{\pi}$ and $(n-1) d$ are thus not orthogonal, and their overlap integrals, that are approximately proportional to the offdiagonal Fock matrix elements and reflect the interaction strength, are also reported in Table 3.

Table 3. Matrix elements of the $\left[\mathrm{M}\left(\mathrm{PH}_{3}\right)_{4}\right]^{2+}$ and $\left[\mathrm{M}\left(\mathrm{NH}_{3}\right)_{4}\right]^{2+}$ Fock operators between the metal $(n-1) d$ orbitals and ligand $\sigma_{\pi}$ orbital-combinations that transform as the $e$ irreducible representation of the $T_{d}$ point group ( $F_{d}$ and $F_{\sigma_{\pi}}$, diagonal; $F_{d, \sigma_{\pi}}$, off-diagonal), their overlap integrals $\left(S_{d, \sigma_{\pi}}\right)$, the resultant molecular orbital energies $\left(E_{M O}\right)$ obtained from diagonalizing the $2 \times 2$ Fock matrix, and the Natural Population of the low-lying MO on the metals (M\%). ${ }^{\text {a }}$ All energy quantities are in the unit of eV.

\begin{tabular}{|l|c|c|c|c|c|r|}
\hline & $F_{d}$ & $F_{\sigma_{\pi}}$ & $F_{d, \sigma_{\pi}}$ & $S_{d, \sigma_{\pi}}$ & $E_{M O}$ & $\mathrm{M} \%$ \\
\hline$\left[\mathrm{Zn}\left(\mathrm{PH}_{3}\right)_{4}\right]^{2+}$ & -22.94 & -19.51 & -0.97 & 0.032 & $-22.95,-19.48$ & 99 \\
\hline$\left[\mathrm{Cd}\left(\mathrm{PH}_{3}\right)_{4}\right]^{2+}$ & -23.75 & -19.29 & -1.29 & 0.043 & $-23.76,-19.24$ & 99 \\
\hline $\left.\mathrm{Hg}\left(\mathrm{PH}_{3}\right)_{4}\right]^{2+}$ & -21.49 & -19.20 & -1.49 & 0.054 & $-21.49,-19.10$ & 96 \\
\hline & & & & & & \\
\hline$\left[\mathrm{Zn}\left(\mathrm{NH}_{3}\right)_{4}\right]^{2+}$ & -22.60 & -22.72 & -2.00 & 0.059 & $-23.28,-21.96$ & 44 \\
\hline$\left[\mathrm{Cd}\left(\mathrm{NH}_{3}\right)_{4}\right]^{2+}$ & -23.47 & -22.39 & -2.27 & 0.068 & $-23.78,-21.79$ & 79 \\
\hline$\left[\mathrm{Hg}\left(\mathrm{NH}_{3}\right)_{4}\right]^{2+}$ & -21.44 & -22.25 & -2.37 & 0.076 & $-22.61,-20.97$ & 24 \\
\hline
\end{tabular}

${ }^{a}$ Showing M\% for one MO suffices, as M\% and 4L\% add up to 100 in one orbital and the $\mathrm{M}: 4 \mathrm{~L}$ composition in the higher-lying orbital is reversed to the low-lying one. 
It is interesting to note that the overlap and off-diagonal matrix elements roughly satisfy the Wolfsberg-Helmholz relation: ${ }^{11}$

$$
F_{d, \sigma_{\pi}}=K S_{d, \sigma_{\pi}} \frac{F_{d}+F_{\sigma_{\pi}}}{2},
$$

with $K$ ranging from 1.36 to 1.43 for the phosphine (1.43 to 1.50 for the ammine) ions. The proportionality of the off-diagonal Hamiltonian matrix element to the overlap is also at the heart of the extended Hückel theory, ${ }^{12}$ a method that has served one of the authors well over the years.

The $e$ MO energies and NPA results obtained within this contracted orbital space are in quantitative agreement with those obtained from the fully optimized electronic structure results in Table 1, and serve to demonstrate the adequacy of this orbital space.

The $(n-1) \mathrm{d}$ and $\sigma_{\pi}$ energies ( $F_{d}$ and $F_{\sigma_{\pi}}$ ) in the upper half of Table 3 differ by more than $2.3 \mathrm{eV}$, with the $(n-1) d$ being lower. These significant energy gaps impede $\sigma_{\pi}-(n-1) d$ interactions. The $F_{d, \sigma_{\tau}}$ coupling elements are of the order of $-1 \mathrm{eV}$, and are seemingly large enough to couple the the (n1)d and $\sigma_{\pi}$ orbitals, despite the energy gap. However, recall that the interacting orbitals are normalized but non-orthogonal, making $F_{d, \sigma_{z}}$ an overestimated coupling. The effective coupling matrix is, then, $\underline{\underline{F}}-\underline{\underline{S}} E_{M O}{ }^{13}$ For instance, in $\left[\mathrm{Zn}\left(\mathrm{PH}_{3}\right)_{4}\right]^{2+}, F_{d, \sigma_{\pi}}-S_{d, \sigma_{\pi}} E_{M O}=-0.24$ and $-0.35 \mathrm{eV}$ for the two $E_{M O}$ values. The magnitude of the effective coupling is insufficient to overcome the $>2.3 \mathrm{eV} \sigma_{\pi^{-}}(n-1) d$ energy gaps, resulting in relatively pure $\sigma_{\pi}$ and $(n-1) d$ orbitals in the phosphine ion complexes.

Completing our discusion of the "normal" phosphine ions, we note that $\left[\mathrm{Hg}\left(\mathrm{PH}_{3}\right)_{4}\right]^{2+}$ is anomalous within this series. Among the three phosphine ion complexes, it has the smallest $\sigma_{\pi}(n-1) d$ gap and the largest coupling between the two orbitals. Correspondingly, it features the "largest" $\sigma_{\pi}-(n-1) d$ mixing, reflected by the $4 \%$ (0.08 electron) Natural Population transfer between the two orbitals. The diminished gap arises from the higher $5 d$ energy of $\mathrm{Hg}$ relative to the $4 d$ and $3 d$ of $\mathrm{Cd}$ and $\mathrm{Zn} \mathrm{(-}$ 21.49 vs. -23.75 and $-22.94 \mathrm{eV}$ ), a manifestation of the relativistic $d$ expansion. ${ }^{14,15}$ This expansion of $\mathrm{Hg} 5 d$ also favors the $\sigma_{\pi^{-}}(n-1) d \pi$-type overlap and leads to the maximum overlap $(0.054, \mathrm{Hg}, v s .0 .043, \mathrm{Cd}$, and 
$0.032, \mathrm{Zn})$ and coupling ( -1.49 vs. -1.29 and $-0.97 \mathrm{eV})$ in the series under discussion. Despite this, the relativistic anomaly here is not large enough to substantially mix the $\sigma_{\pi}$ and $5 d$.

Turning now to the ammines and their noticeable $\sigma_{\pi}-(n-1) d$ mixing, a similar analysis can be used to explain the mixings seen in Table 2 for $\left[\mathrm{M}\left(\mathrm{NH}_{3}\right)_{4}\right]^{2+}$. The Fock matrix elements are calculated and reported in the lower half of Table 3. The $\mathrm{NH}_{3} \sigma_{\pi}$ orbitals lie lower in energy than those of $\mathrm{PH}_{3}$, about $-22 \mathrm{vs}-19 \mathrm{eV}$ in the respective families of ions. This is consistent with the electronegativities of $\mathrm{N}$ and $\mathrm{P}$ - the $\sigma_{\pi}$ energy in free $\mathrm{NH}_{3}$ is lower than that in free $\mathrm{PH}_{3}(-12.68 \mathrm{vs}-10.68 \mathrm{eV})$. The lower-lying $\mathrm{NH}_{3} \sigma_{\pi}$ orbitals are closer in energy to the metal $d$ orbitals, with a maximum gap of $1.08 \mathrm{eV}$ for $\left[\mathrm{Cd}\left(\mathrm{NH}_{3}\right)_{4}\right]^{2+}$. This makes the $\sigma_{\pi}(n-1) d$ interaction stronger than in the phosphine complexes.

In Fig. 5, we show schematically the orbital interaction of $\left[\mathrm{M}\left(\mathrm{NH}_{3}\right)_{4}\right]^{2+}$. The origin of the unexpected orbital mixing observed in the ammine complexes is, clearly, due to the significantly smaller separation in energy of the $\sigma_{\pi}$ and $(n-1) d$ orbitals.

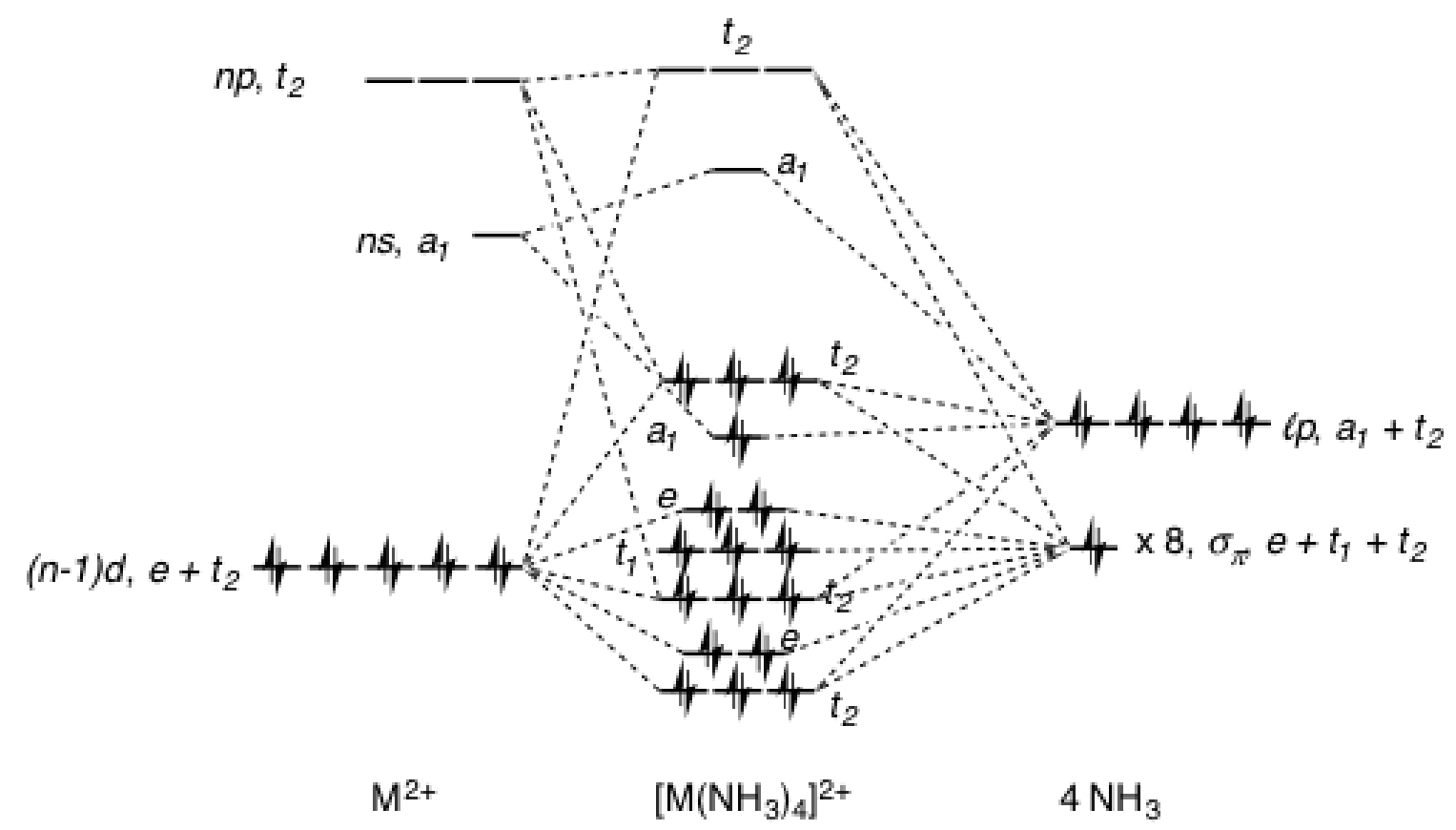

Fig. 5. Schematic orbital interaction diagram for $\left[\mathrm{M}\left(\mathrm{NH}_{3}\right)_{4}\right]^{2+}$. The lowest $e$ and $t_{2}$ levels ( $t_{1}$ and the second lowest $t_{2}$ also) are close in energy (Table 2 ) 
and their relative positions in this schematic diagram do not represent their actal energy ordering.

Besides the smaller $\sigma_{\pi}-(n-1) d$ energy gap, the $\sigma_{\pi}-(n-1) d$ couplings and overlaps are more substantial in the ammine than in the phosphine ion complexes. This is attributed to the general finding ${ }^{16,17}$ that $p$-block elements other than those of the second period have low propensity for $\pi$ type overlap, $\pi$-bonding in general. Both the smaller gap and the larger couplings shape the pronounced $\sigma_{\pi^{-}}(n-1) d$ mixings of $\left[\mathrm{M}\left(\mathrm{NH}_{3}\right)_{4}\right]^{2+}$ shown in Table 2.

The variable extent of $\sigma_{\pi}-(n-1) d$ mixing in the three ammine ion complexes merits further examination. The mixing is reduced from $\left[\mathrm{Zn}\left(\mathrm{NH}_{3}\right)_{4}\right]^{2+}(41: 59)$ to $\left[\mathrm{Cd}\left(\mathrm{NH}_{3}\right)_{4}\right]^{2+}(77: 23)$, because the lowering of the $d$ orbital energy from $\mathrm{Zn}$ to $\mathrm{Cd}$ increases its energy "distance" (from 0.12 higher than to $1.08 \mathrm{eV}$ lower than $\sigma_{\pi}$ ) from the $\mathrm{NH}_{3} \sigma_{\pi}$ orbitals. This $d$ energy-lowering is also reflected by the increase of metal contribution in the lower e $\mathrm{MO}$ from $41 \%$ to $77 \%$. For $\left[\mathrm{Hg}\left(\mathrm{NH}_{3}\right)_{4}\right]^{2+}$, the relativistic $5 d$ expansion ${ }^{14.15}$ raises the $5 d$ energy $0.81 \mathrm{eV}$ higher than that of the $\sigma_{\pi}$ i it reduces the metal contribution in the lower e $\mathrm{MO}$ to $23 \%$. The nearly degenerate $3 d$ and $\sigma_{\pi}$ orbitals make for the most pronounced $\sigma_{\pi}-(n-1) d$ mixing in $\left[\mathrm{Zn}\left(\mathrm{NH}_{3}\right)_{4}\right]^{2+}$. Fig. 6 shows the one component of the degenerate bonding (a) and antibonding (b) $e$ orbitals in $\left[\mathrm{Zn}\left(\mathrm{NH}_{3}\right)_{4}\right]^{2+}$; note how "covalent" they appear.
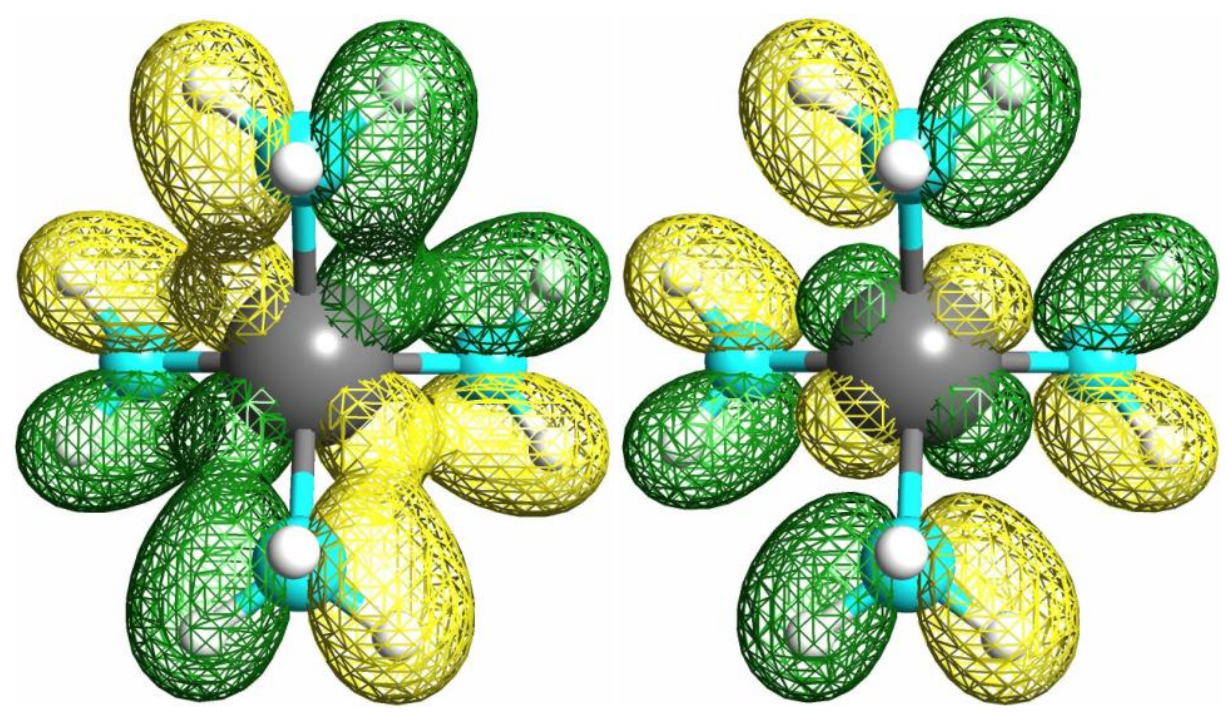

(a) $-23.36 \mathrm{eV}$
(b) $-21.98 \mathrm{eV}$

Fig. 6. The two e occupied MOs in $\left[\mathrm{Zn}\left(\mathrm{NH}_{3}\right)_{4}\right]^{2+}$ with their energies shown below them.

\section{Can The Anomalous Orbital Mixing Be Observed?}

The $\sigma_{\pi^{-}}(n-1) d$ mixing in the $e$ MOs of $\left[\mathrm{M}\left(\mathrm{NH}_{3}\right)_{4}\right]^{2+}$ does not affect bond strengths or geometries. Any bonding effects due to the low-energy $e$ $\mathrm{MO}$ are counteracted by the antibonding effects of the high-energy e MO, as they are both occupied. In other words, the bonding and antibonding $e$ MOs, not that different in energy, may be recombined to form pure, noninteracting metal $d$ orbitals and ligand $\sigma_{\pi}$ orbitals, leaving the KohnSham determinant and the electron density of the complex ion unchanged.

Still, the mixing is substantial in the canonical orbitals. Can it be observed experimentally? Valence-to-core X-ray emission spectroscopy (V2C XES) provides, in principle, a way. ${ }^{18-21}$ When $\mathrm{X}$-ray photoionization generates a hole in one of the core orbitals of the metal, $2 p$ say, both the electrons from either bonding or antibonding $e$ MOs can fill the hole by energetically demoting with concomitant photon ejection. Since the donor orbitals in these cases both have significant metal $d$ contributions, substantial transition dipole moments follow. Two distinguishable $e$-to-core transitions in V2C XES would strongly support the $\sigma_{\pi^{-}}(n-1) d$ mixing. Complications from splitting of $\mathrm{M} 2 p$ by spin-orbit coupling (SOC) can be mitigated by photoexcitation at energies between the well-separated $2 p_{1 / 2}$ $\left(L_{2}\right)$ and $2 p_{3 / 2}\left(L_{3}\right)$ edges, yielding a state with a principally $2 p_{3 / 2}$ core hole.

We note that the energy splitting between the two $e$ MOs does not exceed $1.8 \mathrm{eV}$ in Table 2 for the three ammine ions. Given current technical limitations, such a modest splitting will be difficult to resolve in V2C XES measurements. Also, distinguishing between $e$-to-core transitions and the close-lying $t_{2}$-to-core transitions may prove challenging. This is especially true for $\left[\mathrm{Hg}\left(\mathrm{NH}_{3}\right)_{4}\right]^{2+}$, where substantial spin-orbit coupling (SOC) mixes the $e$ and $t_{2}$ MOs.

However, it is not necessary that we constrain ourselves to the two $e$ MOs. The $\sigma_{\pi^{-}}(n-1) d$ mixing occurs in $t_{2}$ MOs as well. Overall, these orbital 
mixings, regardless whether in $e$ or $t_{2} \mathrm{MOs}$, leads to a broader distribution of $d$ contributions in MOs and therefore, broader valence-to- $2 p_{3 / 2}$ transitions.

To elaborate on this idea, we calculate the valence-to- $2 p_{3 / 2}$ emission spectra for the ammine and phosphine ions, shown in Fig. 7 (Figs. S1 and S2 in the Supporting Information provide the decompositions of the transition profiles to the constituent transitions). As expected, the main transition peaks corresponding to the $e$ - and $t_{2}$-to- $2 p_{3 / 2}$ transitions are significantly broader for $\left[\mathrm{M}\left(\mathrm{NH}_{3}\right)_{4}\right]^{2+}$ than for $\left[\mathrm{M}\left(\mathrm{PH}_{3}\right)_{4}\right]^{2+}$.

The details of the spectra warrant further discussion. The main peak in the $\left[\mathrm{Cd}\left(\mathrm{NH}_{3}\right)_{4}\right]^{2+}$ spectrum stems from the $\sigma_{\pi^{-}}(n-1) d$ bonding orbitals with lower transition energy (around $3530 \mathrm{eV}$ ), while the shoulder between 3532 and $3533 \mathrm{eV}$ arises from $\sigma_{\pi}(n-1) d$ antibonding orbitals. This is because the bonding orbitals have larger contributions from $\mathrm{Cd} 4 d$ than the antibonding ones. The situation is reversed in the $\left[\mathrm{Hg}\left(\mathrm{NH}_{3}\right)_{4}\right]^{2+}$ spectrum; the main peak at $12315 \mathrm{eV}$ corresponds to antibonding orbitals, while the lower energy shoulder corresponds to bonding orbitals. As mentioned above, the $\mathrm{Hg} 5 d$ contributes more to the antibonding orbitals due to its relativistic expansion.

For $\left[\mathrm{Zn}\left(\mathrm{NH}_{3}\right)_{4}\right]^{2+}$, although the bonding $e \mathrm{MO}$ has less metal contribution (41:59, Table 2 ) than the antibonding $e$, the adjacent bonding $t_{2} \mathrm{MO}$ has more metal contribution (58:42, Table 2 ) than the antibonding $t_{2}$. The three-fold degeneracy of the $t_{2} \mathrm{MO}$ versus the two-fold degeneracy of the $e \mathrm{MO}$ make the former more dominant and places the main peak at a lower energy of $1006 \mathrm{eV}$, which corresponds to the bonding $\mathrm{MO}$, with the antibonding shoulder at $1007 \mathrm{eV}$. The shoulder is not much lower than the main peak intensity, reflecting the fairly balanced metal and ligand distributions in the bonding and antibonding MOs.

Within the phosphine ions, $\left[\mathrm{Hg}\left(\mathrm{PH}_{3}\right)_{4}\right]^{2+}$ contains more $\sigma_{\pi^{-}}(n-1) d$ mixing (Table 1) than the other two and it features the broadest distribution of valence-to- $2 p_{3 / 2}$ transitions. It is noteworthy that the little peaks at the highest energy arise from $\mathrm{HOMO} t_{2}$-to- $2 p_{3 / 2}$ transitions, reflecting the magnitude of $\ell p-(n-1) d$ antibonding mixing. Although those transitions are more pronounced in ammine than in phosphine ions, they should not be considered evidence of $\sigma_{\pi^{-}}(n-1) d$ mixing. 
Overall, the differences between the ammine and phosphine ions in the calculated valence-to- $2 p_{3 / 2}$ emission spectra are obvious and should be discernable in real spectra. The anomalous $\sigma_{\pi}-(n-1) d$ mixing in the ammine ions is an observable phenomenon.
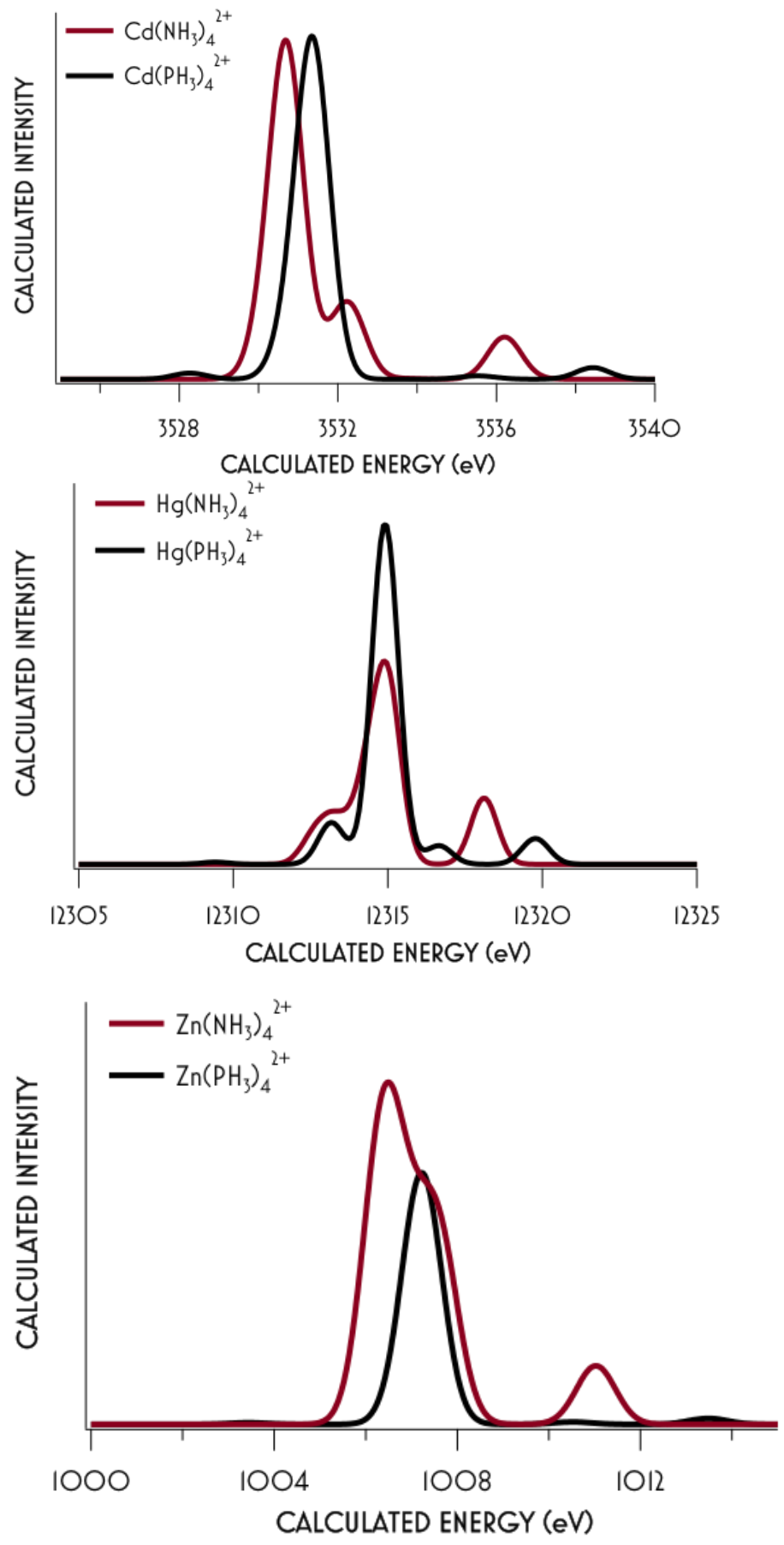
Fig. 7. DFT (M06/def-TZVP-ZORA + SOC) calculated V2C XES (Valence $\rightarrow$ $\left.2 p_{3 / 2}\right)$ of all $\left[\mathrm{M}\left(\mathrm{NH}_{3}\right)_{4}\right]^{2+}$ and $\left[\mathrm{M}\left(\mathrm{PH}_{3}\right)_{4}\right]^{2+}(\mathrm{M}=\mathrm{Zn}, \mathrm{Cd}, \mathrm{Hg})$ ions. In this figure we compare the different transition profiles of the ammine and phosphine complexes. Please refer to Figs. S1 and S2 in the Supporting Information for the detailed description of the transitions.

\section{Structures: An Intriguing Bond Angle Effect}

Table 4 summarizes the calculated geometries of the $\left[\mathrm{M}\left(\mathrm{PH}_{3}\right)_{4}\right]^{2+}$ complexes. No direct experimental information is available for comparison, as the complexes have apparently not been synthesized, possibly due to the inflammability, toxicity, and explosiveness of $\mathrm{PH}_{3}{ }^{22}$ However, M-P distances are available for other $\mathrm{PR}_{3}$ ligands in the coordination sphere of $\mathrm{Zn}$ and $\mathrm{Hg}$, and our calculated bond lengths deviate from them by about 0.1 $\AA$, generally satisfactory agreement.

Table 4. Optimized structural parameters for $\left[\mathrm{M}\left(\mathrm{PH}_{3}\right)_{4}\right]^{2+}$ : M-P bond length $\left(\mathrm{R}_{\mathrm{M}-\mathrm{P}}\right), \mathrm{P}-\mathrm{H}$ bond length $\left(\mathrm{R}_{\mathrm{P}-\mathrm{H}}\right)$, and $\mathrm{H}-\mathrm{P}-\mathrm{H}$ bond angle $\left(\angle_{\mathrm{H}-\mathrm{P}-\mathrm{H}}\right)$. Experimental $\mathrm{R}_{\mathrm{M}-\mathrm{P}}$ for substituted $\mathrm{M}\left(\mathrm{PR}_{3}\right)_{4}{ }^{2+}$ are provided under the calculated ones for comparison.

\begin{tabular}{|c|c|c|c|}
\hline & $\mathrm{R}_{\mathrm{M}-\mathrm{P}} / \AA$ & $\mathrm{R}_{\mathrm{P}-\mathrm{H}} / \AA$ & $\angle_{\mathrm{H}-\mathrm{P}-\mathrm{H}} /{ }^{\circ}$ \\
\hline$\left[\mathrm{Zn}\left(\mathrm{PH}_{3}\right)_{4}\right]^{2+}$ & $\begin{array}{c}2.424 \\
2.370-2.390^{\mathrm{a}}\end{array}$ & 1.403 & $\begin{array}{c}101.9 \\
105^{\mathrm{a}}\end{array}$ \\
\hline$\left[\mathrm{Cd}\left(\mathrm{PH}_{3}\right)_{4}\right]^{2+}$ & 2.565 & 1.403 & 101.5 \\
\hline & 2.655 & & \\
& $2.527-2.547^{\mathrm{b}}$ & 1.404 & 102.1 \\
& $2.552-2.585^{\mathrm{c}}$ & & \\
\hline $\left.\mathrm{Hg}\left(\mathrm{PH}_{3}\right)_{4}\right]^{2+}$ & $2.512-2.613^{\mathrm{d}}$ & & 93.3 \\
& & 1.418 & $93.345^{\mathrm{e}}$ \\
\hline
\end{tabular}

${ }^{\mathrm{a}}$ Experimental $\mathrm{Zn}-\mathrm{P}$ bond length and C-P-C angle for $\left[\mathrm{Zn}\left(\mathrm{PMe}_{3}\right)_{4}\right]\left[\mathrm{BAr}_{4}{ }^{\mathrm{F}}\right]_{2}$ taken from Ref. 2. $\mathrm{BAr}_{4}{ }^{\mathrm{F}}=\mathrm{B}\left\{\mathrm{C}_{6} \mathrm{H}_{3}\left(\mathrm{CF}_{3}\right)_{2}\right\}_{4}$. The $\mathrm{C}-\mathrm{P}-\mathrm{C}$ angle is to compared with the H-P-H angle.

${ }^{b}$ Experimental $\mathrm{Hg}-\mathrm{P}$ bond length for $\left[\mathrm{Hg}\left(\mathrm{PMe}_{2} \mathrm{Ph}\right)_{4}\right]\left[\mathrm{Ta}_{2} \mathrm{OCl}_{10}\right]$ taken from Ref. 4.

${ }^{\mathrm{C}}$ Experimental Hg-P bond length for $\left[\mathrm{Hg}\left(7,8-\left(\mathrm{PPh}_{2}\right)_{2}-7,8-\mathrm{C}_{2} \mathrm{~B}_{9} \mathrm{H}_{10}\right)_{2}\right] \mathrm{CH}_{2} \mathrm{Cl}_{2}$ 
taken from Ref. 5.

${ }^{\mathrm{d}}$ Experimental $\mathrm{Hg}-\mathrm{P}$ bond length for $\mathrm{Hg}(\mathrm{dppe})_{2}{ }^{2+}$ taken from Ref. 6. dppe = $\mathrm{Ph}_{2} \mathrm{PCH}_{2} \mathrm{CH}_{2} \mathrm{PPh}_{2}$.

${ }^{e}$ Experimental $\mathrm{P}-\mathrm{H}$ bond length and $\mathrm{H}-\mathrm{P}-\mathrm{H}$ bond angle for $\mathrm{PH}_{3}{ }^{23}$

For $\mathrm{PH}_{3}$, there is a significant opening up of the $\mathrm{H}-\mathrm{P}-\mathrm{H}$ angle from 93 to $102^{\circ}$ in the complexes. This seemingly "counter-steric" trend is interesting and is explained as follows: to form a stronger dative bond with $\mathrm{M}^{2+}$, the $\mathrm{PH}_{3}$ lone pair requires more $3 p$ character, so as to "protrude" more towards the metal. The hybridization change is in accordance with Bent's rule $^{24}$ that a $p$-block atom's hybrid orbital directed towards an electronegative atom carries more $p$ character; the metal dication "ligand" is highly electronegative.

Correspondingly, we expect less $\mathrm{P} 3 p$ character in the $\mathrm{PH}$ bond pairs. Indeed, the $s: p$ character ratio in the $\mathrm{P}$ hybrid of the $\mathrm{PH}$ bond pair natural bond orbital ${ }^{10}$ (NBO) changes from 15:85 in the free molecule to about 25:75 in the $\left[\mathrm{M}\left(\mathrm{PH}_{3}\right)_{4}\right]^{2+}$ complexes. This reduction of $p$ character in the hybrids opens up the angles between them (recalling the $109.5^{\circ}$ of $\mathrm{C} s p^{3}$ hybrids, $120^{\circ}$ of $\mathrm{C} s p^{2}$ hybrids, and $180^{\circ}$ of $\mathrm{C} s p$ hybrids), and the $102^{\circ} \mathrm{H}-\mathrm{P}-\mathrm{H}$ angle in the ions is close to the $109.5^{\circ}$ of the ideal $s p^{3}$ hybridization limit. The wider $\mathrm{H}-\mathrm{P}-\mathrm{H}$ angle is thus a result of the rehybridizing $\mathrm{P}$ in the ion complexes.

The R-P-R angle also widens upon coordination; a flattening of the $\mathrm{PR}_{3}$ ligand, is observed experimentally in $\mathrm{Zn}\left(\mathrm{PMe}_{3}\right)_{4}{ }^{2+}$. The $\mathrm{C}-\mathrm{P}-\mathrm{C}$ angle is $98.6^{\circ}$ in the free $\mathrm{PMe}_{3}$ molecule ${ }^{25}$ but widens to $105^{\circ}$ in $\mathrm{Zn}\left(\mathrm{PMe}_{3}\right)_{4}{ }^{2+} .^{23}$ The $105^{\circ} \mathrm{C}-\mathrm{P}-\mathrm{C}$ angle compares well with the $102^{\circ}$ of our calculated $\mathrm{H}-\mathrm{P}-\mathrm{H}$ angles, reflecting the accuracy of our methodology. Note that the $105^{\circ} \mathrm{C}-\mathrm{P}$ $\mathrm{C}$ angle has little to do with the steric repulsion between the methyls attached to the same $\mathrm{P}$, as the shortest distance between $\mathrm{H}$ atoms on different methyls is $2.7 \AA$, greater than twice of $\mathrm{H}^{\prime}$ s van der Waals radius $(1.2 \AA) .{ }^{26}$ In addition, any methyl-methyl steric effect would have been observed in the free $\mathrm{PMe}_{3}$ molecule. The change in $\mathrm{PR}_{3}$ pyramidalization on coordination, slight as it is, has some implications for the important Tolman cone angles, so useful in making sense of steric effects of ligands. ${ }^{27,28}$ 
Table 5. Optimized structural parameters for $\left[\mathrm{M}\left(\mathrm{NH}_{3}\right)_{4}\right]^{2+}: \mathrm{M}-\mathrm{N}$ bond length $\left(\mathrm{R}_{\mathrm{M}-\mathrm{N}}\right), \mathrm{N}-\mathrm{H}$ bond length $\left(\mathrm{R}_{\mathrm{N}-\mathrm{H}}\right)$, and $\mathrm{H}-\mathrm{N}-\mathrm{H}$ bond angle $\left(\angle_{\mathrm{H}-\mathrm{N}-\mathrm{H}}\right)$. Experimental $\mathrm{R}_{\mathrm{M}-\mathrm{N}}$ are provided under the calculated ones for comparison.

\begin{tabular}{|c|c|c|c|}
\hline & $\mathrm{R}_{\mathrm{M}-\mathrm{N}} / \AA$ & $\mathrm{R}_{\mathrm{N}-\mathrm{H}} / \AA$ & $\angle_{\mathrm{H}-\mathrm{N}-\mathrm{H}}{ }^{\circ}$ \\
\hline$\left[\mathrm{Zn}\left(\mathrm{NH}_{3}\right)_{4}\right]^{2+}$ & $\begin{array}{c}2.042 \\
2.05^{\mathrm{a}} \\
1.997-2.030^{\mathrm{b}}\end{array}$ & 1.018 & 104.7 \\
\hline$\left[\mathrm{Cd}\left(\mathrm{NH}_{3}\right)_{4}\right]^{2+}$ & 2.202 & 1.017 & 105.1 \\
\hline$\left[\mathrm{Hg}\left(\mathrm{NH}_{3}\right)_{4}\right]^{2+}$ & $\begin{array}{c}2.331 \\
2.247-2.281^{\mathrm{c}}\end{array}$ & 1.016 & 106.1 \\
\hline Free $\mathrm{NH}_{3}$ & & 1.020 & 105.4 \\
\hline
\end{tabular}

${ }^{a}$ Experimental $\mathrm{Zn}-\mathrm{N}$ bond length for $\left[\mathrm{Zn}\left(\mathrm{NH}_{3}\right)_{4}\right] \mathrm{Mo}\left(\mathrm{O}_{2}\right)_{4} \cdot{ }^{29}$

${ }^{\mathrm{b}}$ Experimental $\mathrm{Zn}-\mathrm{N}$ bond length for $\left.\left[\mathrm{Zn}\left(\mathrm{NH}_{3}\right)_{4}\right]\right]_{2} \cdot{ }^{30}$

${ }^{c}$ Experimental $\mathrm{Hg}-\mathrm{N}$ bond length for $\left[\mathrm{Hg}\left(\mathrm{NH}_{3}\right)_{4}\right]\left(\mathrm{ClO}_{4}\right)_{2}$. ${ }^{31}$

${ }^{\mathrm{d}}$ Experimental $\mathrm{NH}_{3}$ bond length and bond angle. ${ }^{32}$

Unlike the case of $\left[\mathrm{M}\left(\mathrm{PH}_{3}\right)_{4}\right]^{2+}$, the literature contains several of structurally characterized $\left[\mathrm{M}\left(\mathrm{NH}_{3}\right)_{4}\right]^{2+}$ for Group 12 metals. Our calculated structures are as expected and agree well with experiment. The calculated $\mathrm{Zn}-\mathrm{N}$ and $\mathrm{Hg}-\mathrm{N}$ distances deviate from experimental values by less than 0.1 $\AA$. We have found no neutron diffraction structures to give us reliable experimental $\mathrm{NH}$ distances, but for free $\mathrm{NH}_{3}$, the theory-experiment agreement is excellent. Unlike the case of $\left[\mathrm{M}\left(\mathrm{PH}_{3}\right)_{4}\right]^{2+}$, the $\mathrm{H}-\mathrm{N}-\mathrm{H}$ angle of the $\mathrm{NH}_{3}$ ligand is similar to that of the free molecule. The $\mathrm{NH}_{3}$ lone pair has high enough $\mathrm{p}$ character $\left(75 \%\right.$ in the $\mathrm{NH}_{3} \mathrm{NBO}$ lone pair, vs. $43 \%$ in the $\mathrm{PH}_{3}$ counterpart) to form a strong $\mathrm{M}-\mathrm{N}$ dative bond and there is no need for the rehybridization that widens the $\mathrm{H}-\mathrm{P}-\mathrm{H}$ angle in the $\mathrm{PH}_{3}$ ligand.

Hessian calculations at the optimized structures found no imaginary frequencies, except for $\left.\left[\mathrm{Cd}\left(\mathrm{NH}_{3}\right)_{4}\right)\right]^{2+}$ and $\left.\left[\mathrm{Cd}\left(\mathrm{PH}_{3}\right)_{4}\right)\right]^{2+}$. The $\left[\mathrm{Cd}\left(\mathrm{NH}_{3}\right)_{4}\right]^{2+}$ ion departed from the ideal tetrahedron, along an $e$ twisting mode. This deformation would eventually take it to square-planar coordination, but the degree of distortion, to $\mathrm{N}-\mathrm{Cd}-\mathrm{N}$ angles of $93^{\circ}$ and $119^{\circ}$ and no change in bond lengths, is not great. And the energy gain is small, $0.09 \mathrm{eV}$. Sterically driven distortion of $\left[\mathrm{M}\left(\mathrm{NR}_{3}\right)_{4}\right]^{2+}$ or $\left[\mathrm{M}\left(\mathrm{PR}_{3}\right)_{4}\right]^{2+}$ are common, but an ammine ligand is unlikely to provoke this, so the effect is probably electronic. Most 
$\left[\mathrm{CdR}_{4}\right]^{2+}$ structures show a close to tetrahedral geometry. An unusual $\mathrm{Cd}(\mathrm{OR})_{2}(\mathrm{THF})_{2}$ compound is square-planar at $\mathrm{Cd},{ }^{33}$ but the $\mathrm{Cd}-\mathrm{O}(\mathrm{THF})$ distances are long, so that the molecule is close to a 2-coordinated $\mathrm{Cd}(\mathrm{II})$ complex with weakly coordinated bases.

The kinetics and mechanism of stereoisomerization of bis-bidentate complexes of $\mathrm{Zn}(\mathrm{II})$ and $\mathrm{Cd}$ (II) (and other ions) have been carefully studied by Minkin, Nivorozhkin, Korobov, and their coworkers. ${ }^{34}$ A variety of mechanisms was observed, including dissociation-recombination, associative, and intramolecular stereoiosmerization. Cd(II) offers some carefully worked out examples of the last, the intramolecular process, with relatively low barriers. ${ }^{37}$

We judge the distortion calculated for $\left[\mathrm{Cd}\left(\mathrm{NH}_{3}\right)_{4}\right]^{2+}$ to be weak, and the discussion of orbital mixing above for $\left[\mathrm{Cd}\left(\mathrm{NH}_{3}\right)_{4}\right]^{2+}$ is based on its tetrahedral structure. Similar e-type imaginary frequencies are also obtained for $\left[\mathrm{Cd}\left(\mathrm{PH}_{3}\right)_{4}\right]^{2+}$. However, geometry optimization starting with a distorted $D_{2 d}$ structure returns directly to a $T_{d}$ structure. It is clear that the potential energy surface for deformation of these complexes from tetrahedral geometry is quite flat.

\section{Conclusions}

$\mathrm{NH}_{3}$ is considered a typical Lewis base ligand, acting mainly through its lone pair electrons. However, the present theoretical study shows unexpected $\pi$-bonding/antibonding interaction involving the $\mathrm{NH} \sigma_{\pi}$ bonding orbitals in $\left[\mathrm{M}\left(\mathrm{NH}_{3}\right)_{4}\right]^{2+}$ cationic complexes with Group 12 metal centers $\mathrm{Zn}$, $\mathrm{Cd}$, and $\mathrm{Hg}$. The interaction between the $\pi$-type $\mathrm{NH} \sigma_{\pi}$ orbitals and the metal centers' valence $d$ orbitals are shown to stem from the small energy gap between them in the cationic system. In contrast, the $\mathrm{PH}$ bond pairs in $\mathrm{PH}_{3}$ are energetically well separated from the metal $d$ orbitals, and our calculations show no interesting interactions.

The interaction we observe computationally has little effect on the geometries of the compounds. Yet it is striking and surprising. We discuss the possibility of using V2C XES to experimentally observe the $\sigma_{\pi}-(n-1) d$ mixing. The broadening of valence-to- $2 p_{3 / 2}$ transitions in the $\left[\mathrm{M}\left(\mathrm{NH}_{3}\right)_{4}\right]^{2+}$ spectra, compared to the sharp transitions in the $\left[\mathrm{M}\left(\mathrm{PH}_{3}\right)_{4}\right]^{2+}$ spectra, may 
serve as evidence for the mixing. Devising further experiments to observe the anomalous orbital mixing we uncovered is an interesting subject for future research.

\section{Theoretical Methods}

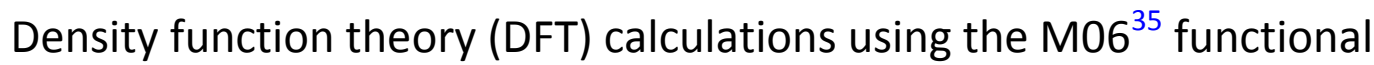
and the SPK-TZP ${ }^{36-45}$ basis sets were carried out to optimize the structures of all phosphine and ammine ions with center metals $\mathrm{Zn}$ and $\mathrm{Cd}$ and obtain their orbitals. For the ions with $\mathrm{Hg}$ center, the SARC-DKH ${ }^{46}$ basis set is used for $\mathrm{Hg}$ and $\mathrm{cc}-\mathrm{pVTZ}{ }^{47}$ basis sets are used for nonmetal atoms. The third order Doublas-Kroll Hamiltonian is used to treat the relativistic effects. The convergence criteria for self-consistent field iteration and geometry optimization are $10^{-6}$ and $10^{-5}$ a.u., respectively. In the calculations of the V2C XES in Fig. 7, the def2-TZVP-ZORA basis sets ${ }^{48}$ are used, and the twocomponent Hamiltonian handles the spin-orbit coupling explicitly. All calculations except for the V2C spectra were done using the GAMESS$\mathrm{US}^{49,50}$ quantum chemistry program package. The V2C spectra are obtained using ORCA. ${ }^{51}$ Gaussian functions with $1 \mathrm{eV}$ full width at half maximum (FWHM) are used to broaden the calculated transition spikes shown in Figs. S1 and S2 in the Supporting Information to the transition profiles shown in Fig. 7.

\section{Associated Content}

Supporting Information

Calculated V2C emission spectra of $\left[\mathrm{M}\left(\mathrm{NH}_{3}\right)_{4}\right]^{2+}$ and $\left[\mathrm{M}\left(\mathrm{PH}_{3}\right)_{4}\right]^{2+}$ complexes with the decomposition of envelops into valence $\mathrm{MO}$-to- $2 p_{3 / 2}$ transitions; coordinates and energies of the six discussed molecular dications in the main text. This material is available free of charge via the Internet at http://hups.acs.org/.

\section{Acknowledgements}


T.Z. thanks the Natural Sciences and Engineering Research Council of Canada for the Banting postdoctoral fellowship (201211BAF-303459236530). R.H. is grateful to the National Science Foundation for its support of this work though Grant CHE-1305872. K.M.L gratefully acknowledges the Cornell University College of Arts and Sciences for startup funding. N. A. acknowledges Cornell Start-up funding. We thank Frank Weinhold for providing us with the NBO6.0 program package. T. Z. is grateful to Mike Schmidt and Mark Gordon for their continuous support of the GAMESS-US program package.

1 Zeng, T.; Cahill, T. J.; Alvarez, S.; Mealli, C.; Hoffmann, R., to be published.
2 Banh, H.; Gemel, C.; Seidel, R. W.; Fischer, R. A. Chem. Comm. 2015, 51, 2170-2172.
${ }^{3}$ Dickie, D. A.; Kemp, R. A. Organometallics 2014, 33, 6511-6518.
${ }^{4}$ Cotton, F. A.; Duraj, S. A.; Roth, W. J. Acta. Cryst. 1985, C41, 881-883.
${ }^{5}$ Kong, L.; Zhang, D.; Su, F.; Li, D.; Dou, J. Bull. Korean Chem. Soc. 2011, 32, 2249-
2252.
${ }^{6}$ Cecconi, F.; Ghilardi, C. A.; Innocenti, P.; Midollini, S.; Orlandini, A.; Ienco, A.; Vacca, A. J. Chem. Soc., Dalton Trans. 1996, 2821-2826.

${ }^{7}$ Albright, T. A.; Burdett, J. K.; Whangbo, M.-H. Orbital Interactions in Chemistry, 2 ${ }^{\text {nd }}$ Ed.; John Wiley \& Sons, Inc.: New Jersey, 2013.

8 Weinhold, F.; Landis, C. R. Valency and Bonding: A Natural Bond Orbital DonorAcceptor Perspective; Cambridge University Press: UK, 2005.

${ }^{9}$ Ballhausen, C. J.; Gray, H. B. Molecular Orbital Theory, An Introduction Lecture Note and Reprint Volume; W. A. Benjamin, Inc: New York, 1965.

${ }^{10}$ Foster, J. P.; Weinhold, F. J. Am. Chem. Soc. 1980, 102, 7211-7218.

11 Wolfsberg, M.; Helmholz, L. J. J. Chem. Phys. 1952, 20, 837-843.

12 Hoffmann, R. J. Chem. Phys. 1963, 39, 1397-1412.

${ }_{13}$ Libit, L.; Hoffmann, R. J. Am. Chem. Soc. 1974, 96, 1370-1383.

${ }^{14}$ Reiher, M.; Wolf, A. Relativistic Quantum Chemistry, The Fundamental Theory of Molecular Science; Wiley-VCH Verlag GmbH \& Co. KGaA: Weinheim, 2009.

15 Pyykkö, P. Chem. Rev. 1988, 88, 563-594.

16 Jutzi, P. Angew. Chem. Int. Ed. 1975, 14, 232-245.

17 Apeloig, Y. "Theoretical aspects of organosilicon compounds" in The chemistry of organic silicon compounds; Patai, S.; Rappoport, Z., Eds.; John Wiley \& Sons, Ltd: Chichester, 1989; p 57-225.

18 Glatzel, P.; Bergmann, U. Coord. Chem. Rev. 2005, 249, 65-95.

${ }^{19}$ Lancaster, K. M.; Finkelstein, K. D.; DeBeer, S. Inorg. Chem. 2011, 50, 6767-6774.

${ }^{20}$ MacMilan, S. N.; Walroth, R. C.; Perry, D. M.; Morsing, T. J.; Lancaster, K. M. Inorg. Chem. 2015, 54, 205-214.

${ }^{21}$ Lee, N.; Petrenko, T.; Bergmann, U.; Neese, F.; DeBeer, S. J. Am. Chem. Soc. 2010, $132,9715-9727$.

${ }^{22}$ Cotton, F. A.; Wilkinson, G.; Murillo, C. A.; Bochmann, M. Advanced Inorganic Chemistry, 6 ${ }^{\text {th }}$ Ed.; John Wiley \& Sons, Inc.: New York, 1999; page 388. 
${ }^{23}$ Haynes, W. M.; Bruno, T. J.; Lide, D. R., Eds; CRC Handbook of Chemistry and Physics, 95 th Ed., Internet Version 2015, p 9-27.

${ }^{24}$ Bent, H. A. Chem. Rev. 1961, 61, 275-311.

${ }^{25}$ Schier, A.; Schmidbaur, H. "P-Donor Ligands" in Encyclopedia of Inorganic Chemistry; Wiley-VCH: Weinheim, 2006.

${ }^{26}$ Rowland, R. S.; Taylor, R. J. Phys. Chem. 1996, 100, 7384-7391.

27 Brown, T. L.; Lee, K. J. Coord. Chem. Rev. 1993, 128, 89-116.

${ }^{28}$ Bunten, K. A.; Chen, L.; Fernandez, A. L.; Poë, A. J. Coord. Chem. Rev. 2002, 223-234, 41-51.

${ }^{29}$ Stomberg, R. Acta Chem. Scand. 1969, 23, 2755-2763.

30 Yamaguchi, T.; Lindqvist, O. Acta Chem. Scand. A 1981, 35, 811-814.

${ }^{31}$ Nockemann, P.; Meyer, G. Z. Anorg. Allg. Chem. 2003, 629, 123-128.

32 Herzberg, G. Electronic spectra and electronic structure of polyatomic molecules; Van Nostrand: New York, 1966.

33 Goel, S. C.; Chiang, M. Y.; Buhro, W. E. J. Am. Chem. Soc. 1990, 112, 6724-6725.

34 Minkin, V. I.; Novorozhkin, L. E.; Korobov, M. S. Uspekhi Khim. 1994, 63, 303-326;

Russ. Chem. Rev. 1994, 63, 289-311 and references therein.

35 Zhao, Y.; Truhlar, D. G. Theor. Chem. Acc. 2008, 120, 215-241.

36 Yamamoto, H.; Matsuoka, O. Bull. Univ. Electro. Comm. 1992, 5, 23.

37 Noro, T.; Sekiya, M.; Koga, T. Theor. Chem. Acc. 2003, 109, 85-90.

38 Tatewaki, H.; Koga, T. J. Chem. Phys. 1996, 104, 8493-8499.

${ }^{39}$ Noro, T.; Sekiya, M.; Koga, T. Theor. Chem. Acc. 1997, 98, 25-32.

40 Tatewaki, H.; Koga, T.; Takashima, H. Theor. Chem. Acc. 1997, 96, 243-247.

${ }^{41}$ Sekiya, M.; Noro, T.; Koga, T.; Matsuyama, H. J. Mol. Struct. (Theochem) 1998, 451, 61-60.

42 Koga, T.; Tatewaki, H.; Matsuyama, H.; Satoh, Y. Theor. Chem. Acc. 1999, 102, 105111.

${ }^{43}$ Noro, T.; Sekiya, M.; Koga, T.; Matruyama, H. Theor. Chem. Acc. 2000, 104, 146152.

${ }^{44}$ Koga, T.; Yamamoto, S.; Shimazaki, T.; Tatewaki, H. Theor. Chem. Acc. 2002, 108, 41-45.

45 Osanai, Y.; Sekiya, M.; Noro, T.; Koga, T. Mol. Phys. 2003, 101, 65-71.

46 Pantazis, D. A.; Chen, X.-Y.; Landis, C. R.; Nesse, F. J. Chem. Theor. Comput. 2008, 4, 908-919.

47 Dunning, T. H. J. Chem. Phys. 1989, 90, 1007-1023.

48 Weigend, F., Ahlrichs, R. Phys. Chem. Chem. Phys. 2005, 7, 3297-3305.

${ }^{49}$ Schmidt, M. W.; Baldridge, K. K.; Boatz, J. A.; Elbert, S. T.; Gordon, M. S.; Jensen, J. H.; Koseki, S.; Matsunaga, N.; Nguyen, K. A.; Su, S.; Windus, T. L.; Dupuis, M.; Montgomery, J. A. J. Comput. Chem. 1993, 14, 1347-1363.

50 Gordon, M. S.; Schmidt, M. W. "Advances in electronic structure theory: GAMESS a decade later" in Theory and Applications of Computational Chemistry: the first forty years; Dykstra, C. E., Frenking, G., Kim, K. S., Scuseria, G. E., Eds.; Elsevier: Amsterdam, 2005.

${ }^{51}$ Neese, F. WIREs Comput. Mol. Sci. 2012, 2, 73-78. 


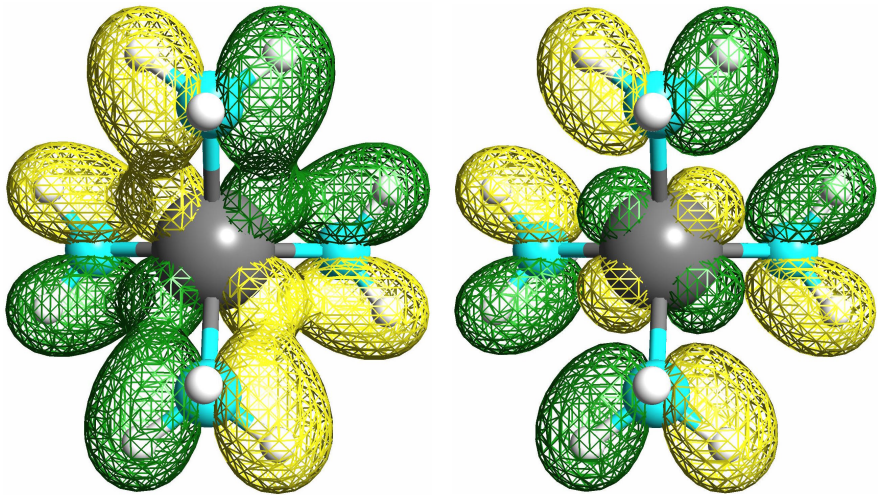

